\title{
OBAMA: Uma Plataforma para Inovação e Colaboração na Prática Docente
}

\author{
Amanda Maria Domingos de Oliveira ${ }^{1}$, Samuel Danta Batista ${ }^{2}$, Nelson Ion de \\ Oliveira ${ }^{2}$, Dennys Leite Maia ${ }^{2}$
}

\author{
${ }^{1}$ Centro de Educação - Universidade Federal do Rio Grande do Norte \\ ${ }^{2}$ Instituto Metrópole Digital - Universidade Federal do Rio Grande do Norte \\ Av. Sen. Salgado Filho, 3000 - Lagoa Nova, CEP: 59.078-970 - Natal - RN - Brasil \\ \{samueldantas7, amanda.marry\} @hotmail.com, \{nelson, dennys\}@imd.ufrn.br
}

Resumo. Este artigo apresenta a Plataforma Objetos de Aprendizagem para Matemática (OBAMA), desenvolvida com o propósito de oferecer ao professor da Educação Básica acesso, em único endereço web, ao maior número de objetos de aprendizagem (OA) e espaço para visualizar e produzir, colaborativamente, planos de aula com os recursos disponibilizados e práticas pedagógicas inovadoras em Matemática. O OBAMA disponibiliza mais de 500 OA, classificados por critérios pedagógicos e técnicos, que contemplam dispositivos desktop e mobile. A plataforma possui sistema de busca por OA por nome, nivel de ensino da Educação Básica, temas curriculares da Matemática e descritores da Prova Brasil, além de uma função para a produção colaborativa de planos de aula.

\section{Cenário de uso}

Atualmente, muito se tem discutido sobre as possibilidade de inovação da prática docente em sala de aula a partir da integração das Tecnologias Digitais da Informação e Comunicação (TDIC). Esses recursos permitem, por exemplo, o desenvolvimento do trabalho colaborativo, oportunizando que os usuários sejam criadores e co-autores de conteúdos e serviços independente de encontrarem-se no mesmo espaço ou ao mesmo tempo [Santana, Campos-Pinto e Costa 2015].

Nesse contexto é fundamental que o currículo escolar e o planejamento docente contemplem o uso das TDIC, dado que estão cada vez mais presentes no cotidiano de alunos e professores e possuem potencial para contribuir na aprendizagem e no ensino em diferentes dimensões. Os Objetos de Aprendizagem (OA), por exemplo, podem apoiar o ensino e a aprendizagem da Matemática promovendo a representação e simulação de situações do cotidiano, de forma a facilitar que o aluno apreenda e compreenda os conceitos matemáticos [Castro-Filho et al, 2016].

Atualmente, a principal fonte de criação e disseminação de informação são as comunidades virtuais. Isso ocorre pelo fato de os usuários membros das comunidades virtuais, em redes sociais, por exemplo, serem membros voluntários que se mantêm ativos por seus interesses em comum, independente de suas localizações no Globo. Essas comunidades desempenham, também, o papel de centros de compartilhamento de experiência e construção de conhecimento, nos quais a aprendizagem está intrínseca à ação [Dias, 2004]. Portanto, pode-se concluir que o trabalho colaborativo entre professores apresenta potencial para enriquecer sua maneira de pensar, agir e resolver problemas, criando possibilidades de sucesso em sua prática pedagógica [Damiani, 2008]. A existência de uma ferramenta para este fim pode potencializar o desenvolvimento do trabalho colaborativo por possibilitar o compartilhamento e a produção de 
conteúdo entre grupos de professores. Isso é relevante pois, como destaca Amiel (2012) ao mencionar um cenário comum à prática docente que o planejamento de uma aula, em que o professor primeiro busca por um recurso digital, depois o relaciona com outros que já conhece, bem como com práticas que já desenvolve, está criando uma nova tecnologia. Entretanto, o autor chama atenção que o "último passo, compartilhar, é o menos comum. Somente com o compartilhamento desses recursos é que conseguimos fechar o círculo virtuoso da criação [Amiel, 2012, p. 26]. É nesse sentido que a Plataforma OBAMA pretende contribuir: apoiar professor no planejamento colaborativo e compartilhamento dos saberes que eles dispõem.

Com a proposta de oferecer aos professores que ensinam Matemática na Educação Básica um ambiente que disponibilize, em único endereço web, o maior número de OA para as suas aulas, foi desenvolvida a Plataforma Objetos de Aprendizagem para Matemática (OBAMA). A referida plataforma, oferece aos professores a escolha pela etapa de ensino, tema curricular e a confiabilidade das características pedagógicas desses recursos, além de espaço para produção colaborativa, consulta e compartilhamento de planos de aula.

\section{Desenvolvimento}

O desenvolvimento da atual versão do OBAMA ${ }^{1}$ foi iniciado após o encerramento do primeiro ciclo de formação de professores, ofertado pelo mesmo grupo que desenvolveu a plataforma. Durante as formações foram coletados relatos e feedbacks dos participantes a fim de identificar possíveis erros a serem corrigidos ou sugestões de melhorias que permitissem aprimorar a plataforma e melhor atender as necessidades dos usuários.

Pensando na dificuldade que um profissional da educação pode enfrentar ao interagir com a interface de um sistema de busca ao qual não está familiarizado, definiu-se que logo ao acessar a plataforma, o professor seria apresentado a uma das principais funcionalidades da plataforma: o sistema de busca por OA. Realizada a pesquisa por OA, são apresentados, então, os atributos de busca que foram elencados a partir de critérios pedagógicos e técnicos. Portanto, esses são os metadados explorados no sistema de busca por OA do OBAMA pois condizem com a realidade do professor, como: o nome do OA, nível de ensino, tema curricular e descritores da Prova Brasil, definidos de acordo com os Parâmetros Curriculares Nacionais (PCN) de Matemática, além das unidades temáticas da Base Nacional Comum Curricular (BNCC) que estão em fase de implementação

Para o OBAMA foram catalogados OA para dispositivos desktop e mobile, dando preferência aos OA de licenças livres e criativas, ou apenas gratuitos, visando garantir a disponibilidade desses recursos de forma gratuita e permanente. No caso dos aplicativos para dispositivos móveis, foi dada preferência aos que funcionam em sistema operacional Android, por ser um sistema presente na maioria das marcas que produzem tablets e smartphones, além de funcionar em dispositivos de baixo custo, possibilitando o acesso de um maior número de pessoas. A plataforma OBAMA dispõe, também, de um espaço para produção, compartilhamento e produção colaborativa de planos de aula.

O usuário, quando cadastrado e logado na plataforma, poderá indicar a inclusão de novos OAs a serem adicionados no repositório, após uma validação da equipe mantenedora do OBAMA. Assim como os OAs, os planos de aula também podem ser filtrados pelos metadados: título, tema curricular, nível de ensino e descritores. Para tanto é preciso que o plano de aula esteja associado a pelo menos um OA (informação não obrigatória para o cadastro de plano de aula). Essa funcionalidade dá ao professor recursos para especificar sua busca de acordo com a

\footnotetext{
${ }^{1}$ Vídeo demonstrativo disponível em: < https://obama.imd.ufrn.br/apresentacao $>$.
} 
habilidade que pretende desenvolver com os seus alunos. Além disso, há a possibilidade de compartilhamento de conteúdo nas redes sociais (Facebook e Twitter).

A plataforma OBAMA foi desenvolvida em linguagem Java com o framework VRaptor implementando o Model View Controller (MVC) que facilita o desenvolvimento web, deixando o código legível e o projeto organizado e, para gerenciamento e armazenamento de dados, utilizou-se o PostgreSQL como sistema de gerenciamento de banco de dados (SGDB). Para o desenvolvimento do módulo colaborativo do plano de aula foi utilizado o Firepad $^{2}$ - uma ferramenta, desenvolvida pela equipe do Google, que disponibiliza componentes que podem ser compartilhados simultaneamente. A escolha das tecnologias utilizadas deu-se por dois fatores: todas estão disponíveis sob licenças que permitem livre utilização, modificação e redistribuição; e a familiaridade dos desenvolvedores com as linguagens de programação e os softwares para desenvolvimento e gerenciamento destas linguagens.

O OBAMA encontra-se disponível para utilização e em processo de registro junto ao Instituto Nacional da Propriedade Industrial (INPI). Entretanto, como é previsto no desenvolvimento de sistemas computacionais, sobretudo aqueles inseridos na filosofia do Software Livre, o OBAMA está em processo contínuo de levantamento de novas funcionalidades e correção de comportamentos inesperados para que a plataforma esteja continuamente evoluindo e melhor servindo seus usuários. As funcionalidades do atual estado dessa plataforma serão apresentadas na seção de apresentação do software.

\section{Apresentação do Software}

A plataforma OBAMA é um sistema web que não necessita de cadastro de usuário para a busca de OA e planos de aula. Porém, é necessário estar cadastrado para poder acessar as funcionalidades de criação e compartilhamento de plano de aula e sugerir OA. Ao acessar a plataforma, o usuário verá a interface inicial (Figura 1) que apresenta o menu superior, composto por seis opções: (i) Início; (ii) Equipe, onde são apresentados os membros do projeto; (iii) Publicações, em que o usuário tem acesso às publicações do grupo de pesquisadores que desenvolvem o OBAMA; (iv) Planos de aula, para a consulta de planos elaborados por usuários do OBAMA que já foram revisados e publicizados; (v) Ajuda, onde ficam disponíveis orientações sobre como usar a plataforma OBAMA; e (vi) Acesse, para que o usuário possa cadastrar-se/logar-se na plataforma e acessar os demais recursos, como submeter planos de aulas e OA.

No rodapé da página inicial, e de todas as páginas da plataforma, estão o link de acesso ao formulário de contato com o suporte técnico e o selo Creative Commons BY-SA ${ }^{3}$.

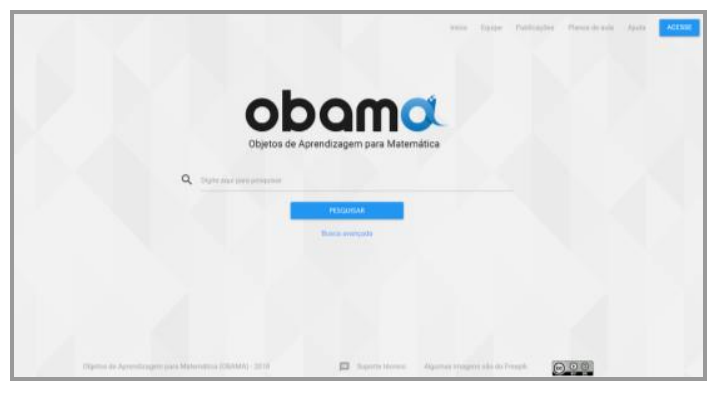

\footnotetext{
2 Disponível em: <https://firepad.io/>.

3 O OBAMA é uma plataforma de código-fonte aberto que permite que outras pessoas utilizem, modifiquem e redistribuam o código-fonte desde que dê os devidos créditos aos desenvolvedores iniciais e mantenham a mesma licença em suas novas versões.
} 
VII Congresso Brasileiro de Informática na Educação (CBIE 2018)

Anais dos Workshops do VII Congresso Brasileiro de Informática na Educação (WCBIE 2018)

Figura 1. Página Inicial da plataforma OBAMA.

Na tela inicial, além do menu superior, é apresentado o campo de busca com o rótulo "Digite aqui para pesquisar", no qual o usuário pode buscar o OA informando termos referentes ao nome do OA, descritor ou nível de ensino, por exemplo. Logo abaixo do campo de busca está disponível, também, o botão "Pesquisar" e o link "Busca avançada" - ambos permitem que o usuário, caso queira, acesse diretamente o formulário de busca avançada.

\subsection{Busca e acesso a OAs}

No formulário de busca avançada, o usuário tem acesso aos filtros de busca textual, Nível de Ensino, Tema Curricular, Descritores e Tipo de plataforma, como mostra a figura 2. Visto que os OAs do OBAMA estão classificados de acordo com os PCN, que norteiam a Prova Brasil, esses campos facilitam o processo de busca, garantindo confiabilidade ao recurso e facilitando o trabalho dos professores na busca por OA em um determinado tema de interesse.

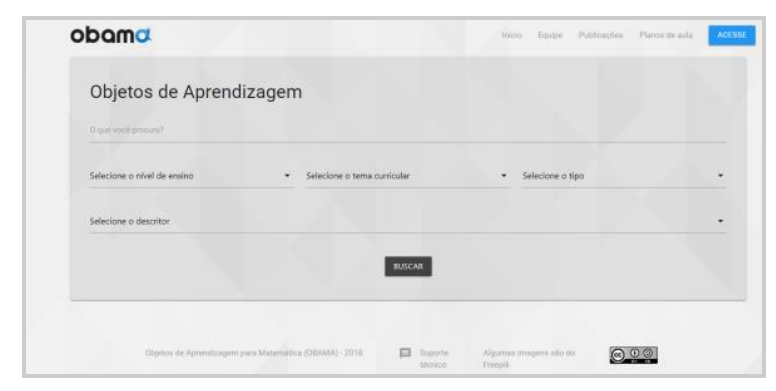

Figura 2. Página de busca de OA na plataforma OBAMA.

Quando são encontrados resultados que atendem aos filtros buscados, os OAs são apresentados como mostra a figura 3. A listagem exibe, para cada OA encontrado, uma imagem relacionada a ele, seu nome e nível de ensino e os três botões: (i) Visualizar, que dá acesso direto ao OA, uma vez que a maior parte dos recursos não demandam instalação para uso; (ii) Mais informações, que o usuário terá acesso à informações sobre o autor do OA, descritores da Prova Brasil e planos de aula associados ao objeto; e (iii) Compartilhar, que permite ao usuário compartilhar o OA nas redes sociais Facebook ou Twitter.

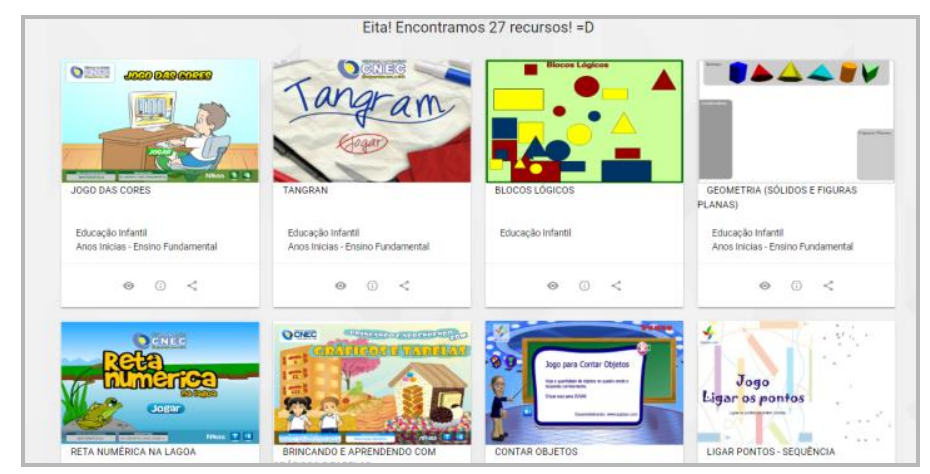

Figura 3. Página de resultados da busca de OA na plataforma OBAMA.

Ao clicar no botão "Mais Informações" (figura 4) são apresentadas informações relacionadas aos autores do OA e classificação por descritores. Destaque-se a informação dos descritores e nível de ensino por auxiliarem o professor em uma pré-avaliação sobre o recurso e sua pertinência para a aula que ele deseja planejar. 
VII Congresso Brasileiro de Informática na Educação (CBIE 2018)

Anais dos Workshops do VII Congresso Brasileiro de Informática na Educação (WCBIE 2018)

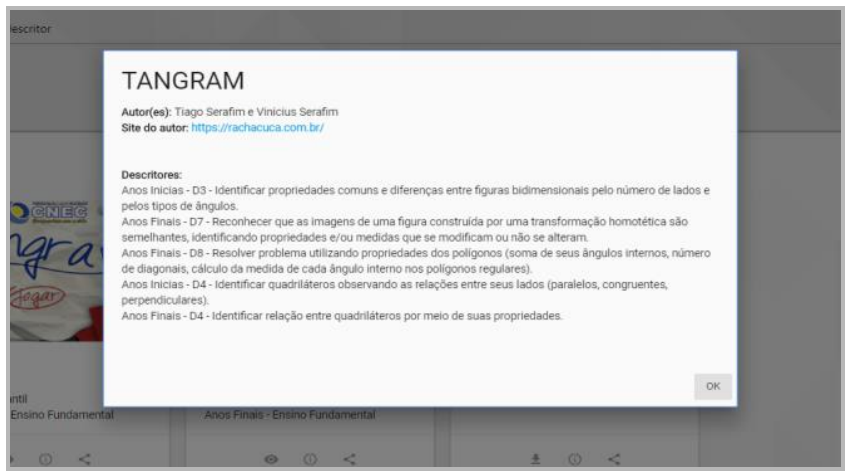

Figura 4. Mais informações sobre o OA.

\subsection{Cadastro no sistema para submissão de plano de aula}

Para acessar as outras funcionalidades do OBAMA, além da busca e visualização de OA e Planos de Aula, é necessário que o usuário realize seu cadastro no sistema. A partir do botão Acesse, do menu superior, o usuário tem acesso ao formulário de login (figura 5). Vale destacar que o usuário pode utilizar sua conta do Google ou Facebook, para fazer login ou cadastrar-se na plataforma. Tal decisão foi tomada com o objetivo de deixar a plataforma com acesso mais facilitado possível ao professor, considerando serviços web que ele já disponha e tenha familiaridade. No formulário de login, como indicado na figura 5 , o usuário terá acesso à opção de "Cadastre-se" que dará acesso o formulário de cadastro.

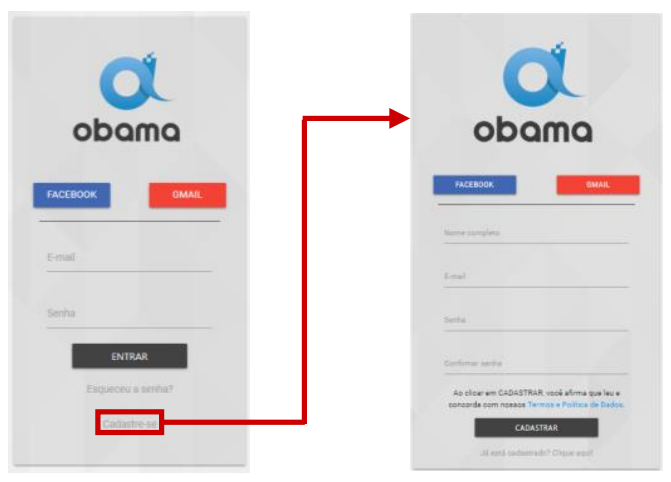

Figura 5. Formulários de login e cadastro.

Com seu cadastro efetivado e realizado o login no sistema, o usuário terá acesso a um outro menu (disposto ao lado esquerdo) no qual estão as opções de cadastro, edição e busca de planos de aula e OA.

\subsection{Menu lateral de navegação}

O menu de navegação lateral posicionado ao lado esquerdo só é visível para usuários cadastrados e logados no OBAMA. O menu contém cinco links de navegação no site: inicio, equipe, publicações, objetos de aprendizagem e plano de aula. As opções plano de aula e objetos de aprendizagem são as únicas opções que contém subitens. Ao selecionar plano de aula, aparecerá as opções: novo, meus planos de aula e buscar; e ao selecionar objetos de aprendizagem aparecerá a opções: buscar e sugerir OA. 


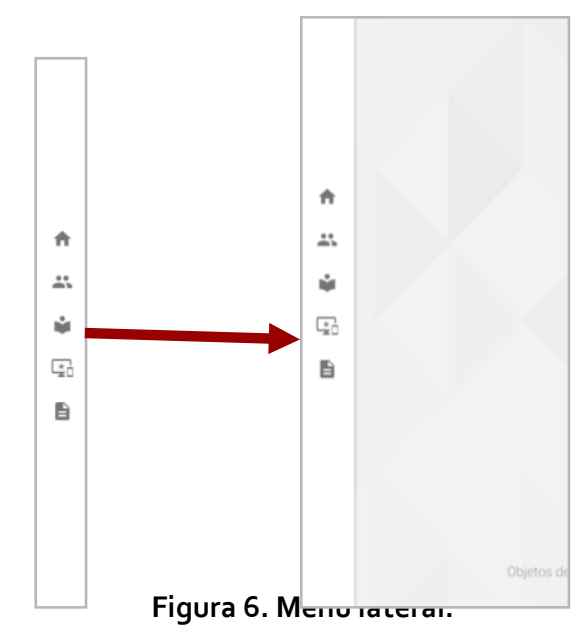

\subsection{Formulário de cadastro de plano de aula}

O formulário de submissão de plano de aula é dividido em três passos, cujos campos apresentam descrições autoexplicativas, de forma a simplificar o entendimento do que deve ser informado para o cadastro do plano de aula. Essa foi uma das demandas identificadas durante as formações de professores oferecidas [Batista et al, 2018]. Por exemplo, o campo que antes tinha o rótulo "Título" foi modificado para "Escreva uma frase curta que defina sua aula". Em qualquer momento do cadastro de plano de aula é possível que usuário salve o atual estado de sua produção ao clicar no botão "Salvar rascunho". Para compartilhar a aula com outros usuários do OBAMA basta clicar no botão "Compartilhar" e então informar o e-mail de seus coautores.

O primeiro passo do cadastro de plano de aula é destinado ao preenchimento de informações gerais, tais como: instituição de ensino, título do plano de aula, ano de ensino e duração da aula, conforme a figura 7 .

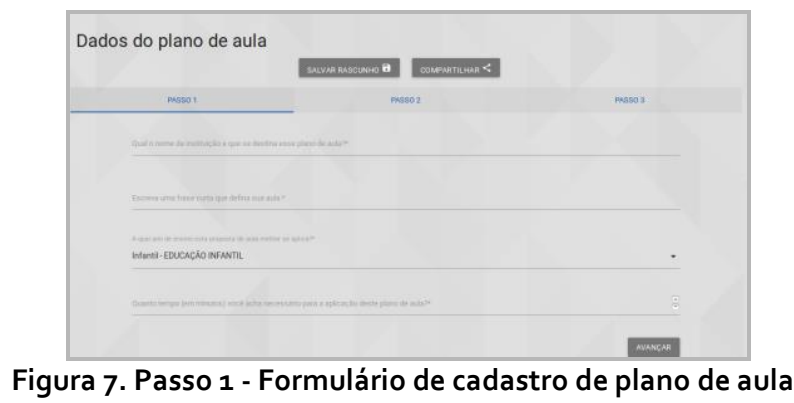

O passo 2 (figura 8) do cadastro de plano de aula é o espaço para o professor descrever os objetivos, aspectos metodológicos, avaliação, recursos e referências do plano de aula. $\mathrm{O}$ campo para descrição desses itens permite ao professor escrever o plano de aula de forma colaborativa e simultânea com outros usuários. Para auxiliar os professores na escrita, cada tópico do formulário possui a indicação do que se espera em cada tópico da descrição do plano de aula. 
VII Congresso Brasileiro de Informática na Educação (CBIE 2018)

Anais dos Workshops do VII Congresso Brasileiro de Informática na Educação (WCBIE 2018)

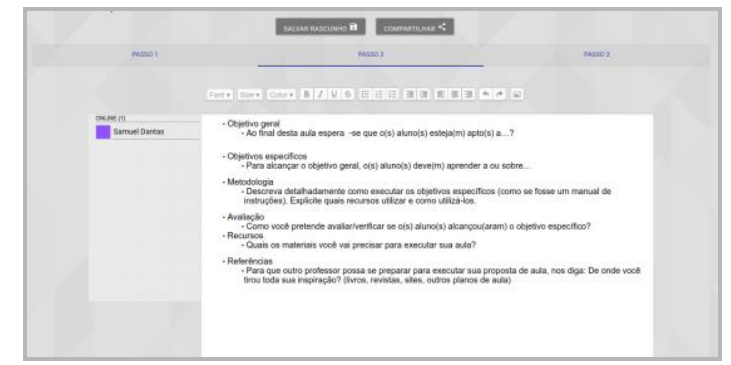

Figura 8. Passo 2 - Formulário de cadastro de plano de aula

Por fim, no passo 3, caso tenha sido utilizado um ou mais OA do OBAMA, o professor poderá referenciar os OA no plano de aula conforme a figura 9. A inclusão dos OA no plano de aula não é obrigatória, porém essa informação possibilita que os planos de aula sejam indexados por tema curricular e descritores dos OA.

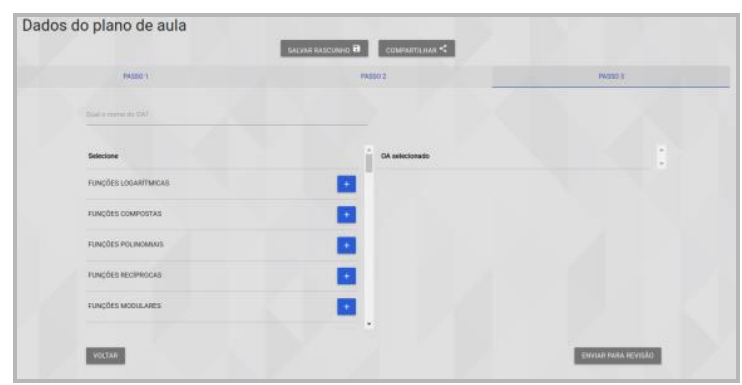

Figura 9: Passo 3 - Formulário de cadastro de plano de aula

\section{Considerações Finais}

Dentre todas as características apresentadas na plataforma OBAMA, destaca-se a classificação de OAs pelos descritores da Prova Brasil e o espaço para criação colaborativa de planos de aula. A classificação de OAs pelos descritores da Prova Brasil proporcionam agilidade na busca de um OA que trabalhe a habilidade desejada pelo professor, essa é uma funcionalidade muito importante que, se levar em consideração a alta carga de trabalho dos professores de escola pública e a dificuldade para encontrar um recurso que o auxilie pode ser um fator motivador aos professores. A consulta e o envio dos planos de aula relacionados aos OAs presentes no OBAMA é outra característica importante, por proporcionar um ambiente de troca de informações, ideias e experiência entre os professores.

Do ponto de vista de inovação, destacamos que ambas as funções da Plataforma OBAMA podem contribuir para o trabalho docente em duas dimensões. A primeira, é o acesso a um repositório de OAs específicos de Matemática, que podem ser buscadas conforme critérios específicos da área de conhecimento. A segunda é a produção de plano de aula que otimiza o momento de planejamento do professor pois, no mesmo ambiente de busca de OA, o docente já tem a opção de produzir o plano de aula.

Destaca-se que o planejamento das atividades pedagógicas dos docentes em escolas que, geralmente, já sincronizam os seus calendários de atividades por ano de ensino, de forma que professores de uma mesma instituição, que estejam em seu momento de planejamento, possam desenvolver seus planos de aulas em colaboração. Essa colaboração pode ser potencializada através do recurso de construção colaborativa e simultânea de plano de aula disponibilizado na plataforma OBAMA. 
VII Congresso Brasileiro de Informática na Educação (CBIE 2018)

Anais dos Workshops do VII Congresso Brasileiro de Informática na Educação (WCBIE 2018)

Entretanto, destacamos ainda que, a conjugação de ambas funcionalidades da Plataforma OBAMA de forma colaborativa contribui ainda para o desenvolvimento profissional docente. Afinal, o OBAMA oportuniza que um professor, que nunca utilizou um OA em suas aulas, possa fazê-lo a partir de um plano de aula elaborado por outro profissional. Outro aspecto, é oportunizar que diferentes professores possam planejar as aulas com TDICs o que pode contribuir para, por exemplo, o planejamento entre o professor do laboratório e o professor da sala de aula.

Ressalta-se que, dado o momento para submissão deste trabalho, os OA da Plataforma OBAMA estão em fase de reclassificação de acordo com a recém publicada BNCC, de forma que o sistema satisfaça às demandas dos professores da forma mais atualizada. Em paralelo, o sistema de verificação de links mantém a equipe de desenvolvimento alerta sobre a disponibilidade de acesso aos OA.

\section{Referências}

Amiel. T. (2012). Educação aberta: configurando ambientes, práticas e recursos educacionais. In: Santana, B.; Rossini, C; Pretto, N. De L. (Orgs.). Recursos Educacionais Abertos: práticas colaborativas políticas públicas. Salvador: Edufba. p.17-33.

Castro-Filho, J. A. de; Maia, D. L.; Castro, J. B. de; Barreto, A. L. de O.; Freire, R. S. (2012). Das tabuletas aos tablets: tecnologias e aprendizagem da Matemática. In: Castro-Filho, J. A. de; Barreto, M. C.; Barguil, P. M.; Maia, D. L.; Pinheiro, J. L. (Orgs.). Matemática, cultura e tecnologia: perspectivas internacionais. Curitiba: CRV, p.13-34.

Damiani, M. F. (2008). Entendendo o trabalho colaborativo em educação e revelando seus benefícios. In: Educar em revista, v.24, n.31, p.213-230.

Dias, P. (2004). Comunidades de aprendizagem e formação on-line. In: Nova Formação: revista semestral sobre formação a distância \& e-Learning. p.14-17.

Batista, S. D., et al. (2018). Processo de desenvolvimento de uma ferramenta destinada à elaboração de Planos de Aula de forma colaborativa. In: Anais do III Congresso sobre Tecnologias na Educação - Ctrl+E 2018. Fortaleza.

Santana, C. M. H.; Campos-Pinto, A. de; Costa, C. J. D. S. A. (2015). A ubiquidade das TDIC no cenário contemporâneo e as demandas de novos letramentos e competências na EAD. In: EaD EmRede-Revista de Educação a Distância, v.2., n.1, p.100-115. 